\title{
Frontal Artery
}

National Cancer Institute

\section{Source}

National Cancer Institute. Frontal Artery. NCI Thesaurus. Code C52856.

A blood vessel also known as the supratrochlear artery that arises from the ophthalmic artery and ascends on the forehead. 